\title{
Spinal cord herniation repair with microstaples: case report
}

\author{
Pedro David Delgado-López, MD, ${ }^{1}$ Cecilia Gil-Polo, MD, PhD, ${ }^{1}$ Vicente Martín-Velasco, MD, ${ }^{1}$ \\ Javier Martín-Alonso, MD, ${ }^{1}$ Ana María Galacho-Harriero, MD, ${ }^{1}$ and Elena Araus-Galdós, MD²
}

Departments of ${ }^{1}$ Neurosurgery and ${ }^{2}$ Neurophysiology, Hospital Universitario de Burgos, Spain

\begin{abstract}
Idiopathic spinal cord herniation (ISCH) is a relatively rare and frequently misdiagnosed condition. It preferentially affects women and causes progressive thoracic myelopathy that presents as a Brown-Séquard syndrome or as spastic paraparesis. Although its etiology and pathogenesis are controversial, ISCH is characterized by the presence of an anterior dural defect that allows the incarceration of a segment of the cord. Typically, a C-shaped ventral displacement and kinking of the cord are visible on sagittal MRI. Surgery aimed at stopping or reversing myelopathic symptoms is usually recommended for symptomatic patients. Surgical options include reduction of the hernia and direct suturing, or enlargement of the dural defect, with or without patching. Suturing under the cord in a very tight space can be troublesome and may lead to neurological deterioration. The authors present the case of a symptomatic ISCH in which nonpenetrating titanium microstaples were used to close the dural defect after cord reduction. The patient experienced a good outcome, and the follow-up MRI study showed adequate cord repositioning and stability of the suture. The use of microstaples, which allows for an easier and faster dural closure than conventional suturing, is a novel technical adjunct that has not been previously reported for this condition. In addition, microstaples produce minimal metallic artifact that does not hinder the quality of follow-up MR images.
\end{abstract}

https://thejns.org/doi/abs/10.3171/2016.8.SPINE16318

KEY WORDS cord herniation; myelopathy; microstaples; dural defect; spinal cord injury

I DIOPATHIC spinal cord herniation (ISCH) is a relatively rare and easily misdiagnosed condition. Since its first description in $1974,{ }^{16}$ approximately 200 cases have been reported. ${ }^{3}$ In fact, reports of several cases from single centers indicate that this condition occurs more frequently than previously believed. ${ }^{3}$ ISCH is generally found in middle-aged adults, mostly women. ${ }^{1-4,9,12}$ Although its etiology remains unclear, ISCH has been suggested to be either congenital or somehow due to trauma. ${ }^{-4,9,12}$ This condition is characterized by a ventral displacement of the spinal cord through a dural defect, usually at the thoracic level. ISCH produces progressive myelopathy and presents as spastic paraparesis or as a Brown-Séquard syndrome, although some patients may be asymptomatic. ${ }^{1-4,9,12}$ MRI demonstrates a ventral $\mathrm{C}$-shaped kinking of the thoracic cord on sagittal views. Moreover, cerebrospinal fluid flow in the subarachnoid space posterior to the herniated spinal cord is visible on phase-contrast pulse cine MRI, which helps to distinguish it from an arachnoid cyst. ${ }^{1,2,13}$ Imagama et al. proposed a radiological classification of ISCH according to the severity and displacement of herniation based on sagittal and axial imaging findings. ${ }^{5}$ Surgery is generally recommended to correct the incarceration and minimize the risk of progressive cord damage. . $^{-4,9,10,13,14}$

\section{Case Report}

History and Examination

A 33-year-old woman with an unremarkable medical history presented with a 20 -month history of progressive back pain followed by numbness in her right lower limb. No previous trauma or history of spinal infection was reported. Neurological examination revealed a Brown- 


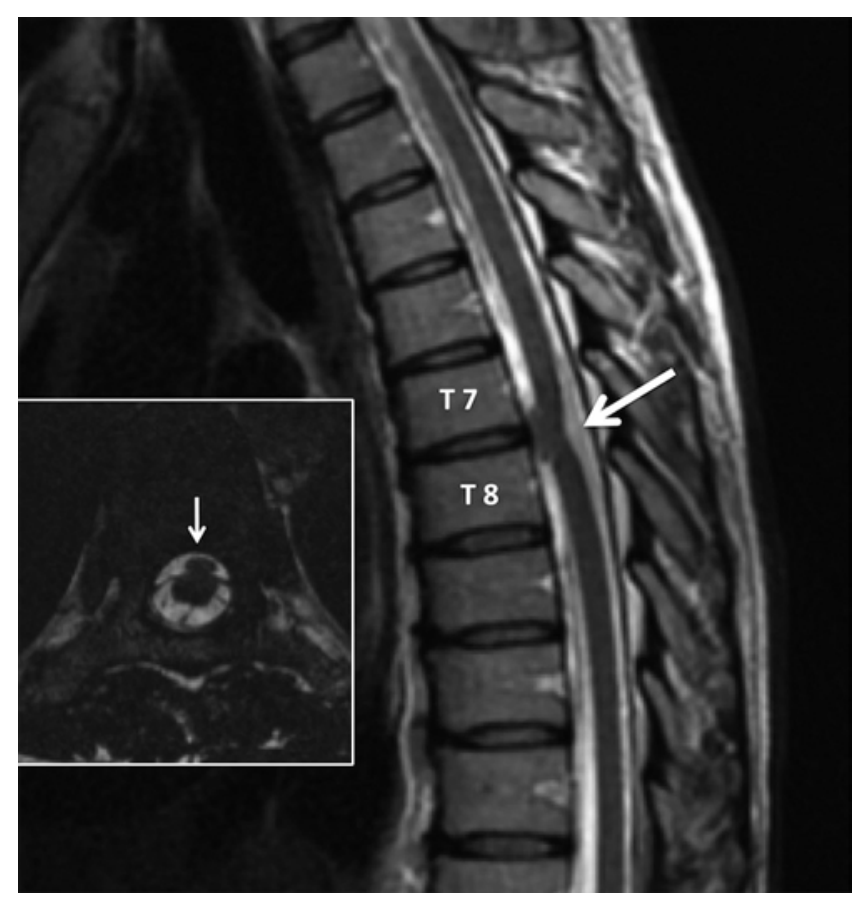

FIG. 1. Preoperative axial (inset) and sagittal T2-weighted MR images showing anterior spinal cord herniation at the T7-8 level (arrows).

Séquard syndrome with mild weakness in the left lower limb and an impaired sense of temperature and pain below the T-7 dermatome level on the right side. The patient reported sphincter dysfunction. MRI revealed a left anterolateral spinal cord displacement at the T7-8 vertebral level, with an obvious kinking and incarceration of the cord but without changes in MR signal intensity (Fig. 1). Intradural masses or cysts were excluded, and a diagnosis of transdural spinal cord herniation was suggested. Surgery was recommended, and written consent was obtained from the patient.

\section{Operation}

After induction of general anesthesia, the surgical procedure was carried out with the patient placed prone. A midline bilateral posterior approach was performed under fluoroscopic guidance for identification of the spinal level. The patient received prophylactic antibiotic treatment (cefazolin, $2 \mathrm{~g}$ ) at the beginning of the operation. Steroid treatment was not administered. The procedure was performed using neurophysiological monitoring, which included somatosensory and motor evoked potentials and D-wave monitoring. The patient underwent a bilateral T7-8 laminectomy, followed by midline dural incision and bilateral division of the dentate ligaments for better mobilization of the cord and exposure of the incarcerated cord segment. The exposed dural defect was slightly widened, both proximally and distally, to facilitate the release of the herniated segment of the cord, which appeared pale and atrophic (Fig. 2). Once the herniated cord portion was repositioned inside the dural sac, an attempt was made to close the dural defect with conventional stitches, but the dural gap was too wide, precluding adequate suturing due to excessive tension between the margins. Eventually, the surgeon decided to use nonpenetrating titanium microstaples (Fig. 2 and Video 1), which turned out to be a much easier and faster way to perform the suturing underneath the cord.

VIDEO 1. Operative video showing the procedure of cord hernia release and suture of the dural defect with nonpenetrating titanium microstaples. SEP = somatosensory evoked potential. Copyright

Pedro David Delgado-López. Published with permission. Click here to view.

This clip suture appeared to be strong and resistant. No dural patches were used. Before closure, a thin membrane was introduced under the cord with the purpose of protecting the cord tissue from the metal staples. This maneuver resulted in a marked affectation of both sensory and motor evoked potentials, so the membrane was quickly removed and the potentials fully recovered within a few minutes. The dorsal dural opening was then sutured and sealed with fibrin glue, and the wound was closed without placing any drainage device.

\section{Postoperative Course}

The patient was allowed to ambulate the next day, and she was uneventfully discharged after 6 days. Sixteen months after surgery, the patient has completely recovered power in her leg, and the sensory loss has markedly improved. The patient is currently able to walk normally and reports no pain or dysesthesia. Spinal MRI after 4 and 15 months confirmed adequate repositioning of the cord and stability of the metallic suture (Fig. 3).

\section{Discussion}

Recognition of ISCH has increased over the past decade, most likely because of the technical advances and the increased availability of spinal MRI. However, this condition remains underrecognized, particularly outside the specialized fields of spinal surgery and neuroradiology, leading to a significant delay in clinical diagnosis. ${ }^{3,4}$ Data from a meta-analysis by Groen et al. reported that the mean interval between the onset of symptoms (usually leg numbness) and surgical intervention for ISCH is 5.2 years, ranging from 6 months to 36 years. ${ }^{4}$ This interval seemed to be longer for patients who developed a BrownSéquard syndrome than for those presenting with spastic paraparesis. ${ }^{4}$

Several etiological mechanisms have been proposed, including unrecognized trauma, congenital meningeal malformation, cerebrospinal fluid flow pulsation, and dural erosion due to a calcified disc or osteophyte. ${ }^{1,2,4,9,12-14}$ The dural defect is most commonly found at the thoracic level, probably because the spinal cord is located more ventrally at this level compared with the cervical and lumbar segments. $1,2,4,9,12-14$ The first neural tract usually affected by cord herniation is the lateral spinothalamic tract, which results in unilateral diminished pain and temperature sensation. As the corticospinal tract becomes involved, progressive weakness and spasticity of the lower limbs may also appear. The dissociated sensory deficit with asymmetrical spastic paraparesis, known as BrownSéquard syndrome, is the most common clinical presentation. ${ }^{1,2,4,13,14}$ 

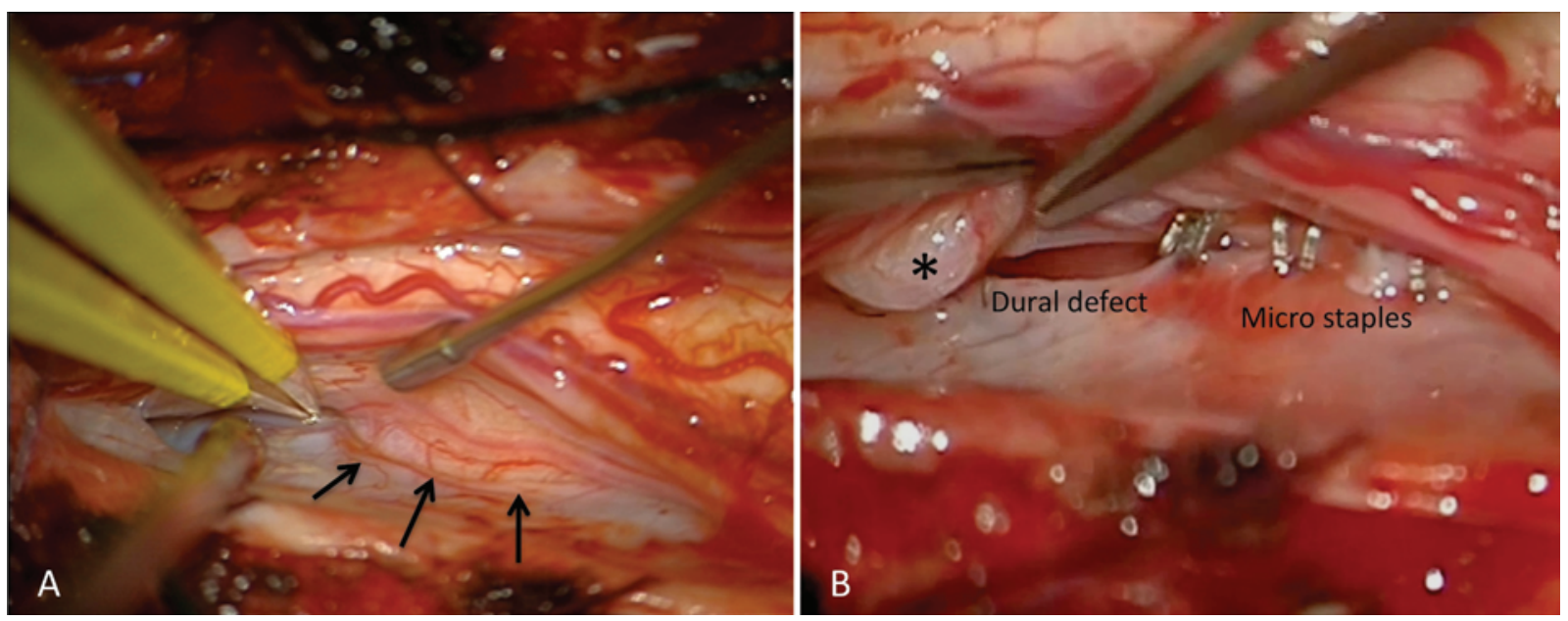

FIG. 2. A: Intraoperative view of the herniated portion of the cord through an anterior dural defect (arrows). B: Dural defect partially sutured with microstaples after reduction of the herniated cord tissue (asterisk).

There is unanimous agreement on the surgical indication for ISCH presenting with progressive and/or severe neurological deficit. In fact, surgery seems to be the only method for reversing or stopping the neurological deterioration occurring in these patients. ${ }^{1,2,4,13,14}$ Results from previous reports indicate that even patients with a long history may benefit from surgery. ${ }^{2}$ However, some authors have highlighted the importance of early surgical treatment to improve the chances of a favorable outcome., ${ }^{3,14}$ The purpose of surgery is to release the incarceration of the cord, relocate it to its normal intradural position, and suture the dural defect to prevent recurrence. ${ }^{4,10,11,14}$ Two main approaches have been reported: either to closure of the defect itself or, conversely, to widen the dural defect to prevent strangulation. ${ }^{1,2,4,8,11,13,14}$ Closure of the defect can be achieved by direct suture or by inserting a ventral patch, with or without glue, once the cord hernia is relocated to its anatomical position. ${ }^{1,4,8,11,13,14}$ However, choosing the best technique remains a matter of debate. Tekkök highlighted the fact that, since the space in which to perform direct suturing under the cord is minimal, attempts to do so may lead to an increased risk of neurological deterioration..$^{13}$ Nakamura et al. recommended widening the dural defect, which is technically easier and safer than suturing and repairing it, as this enlargement seems to provide anatomical stability and prevent recurrence of the hernia. ${ }^{10}$

After surgery, in the majority of cases patients either improve or stabilize. Long-term surgical outcomes are usually favorable and stable without recurrence of ISCH. ${ }^{10}$ However, some patients may experience only mild or transient improvement. ${ }^{2,11}$ Generally, outcome seems to be more favorable in patients presenting with Brown-Séquard syndrome, compared with those with pure spastic paraparesis. ${ }^{10,13}$ Interestingly, the development of postoperative T2-weighted MRI hyperintensity within the cord has been considered a sign of unfavorable outcome. ${ }^{15}$

In the case presented, we primarily attempted to perform direct suturing of the anterior dural defect once the hernia was reduced. We found that there was too much tension between the margins of the defect, causing the suture to loosen. After laborious stitching, we finally decid- ed to use special vascular clips (titanium nonpenetrating microstaples, AnastoClip VCS, LeMaitre Vascular Inc.) to close and secure the dural defect. The clip applicator is very easy to use, and this kind of suture provides stable and strong closure of the dura. Long-term follow-up MRI demonstrated its stability. It is important to highlight that microstaple application is much faster than conventional suturing, which minimizes cord traction and manipulation. Nonpenetrating titanium clips have been successfully

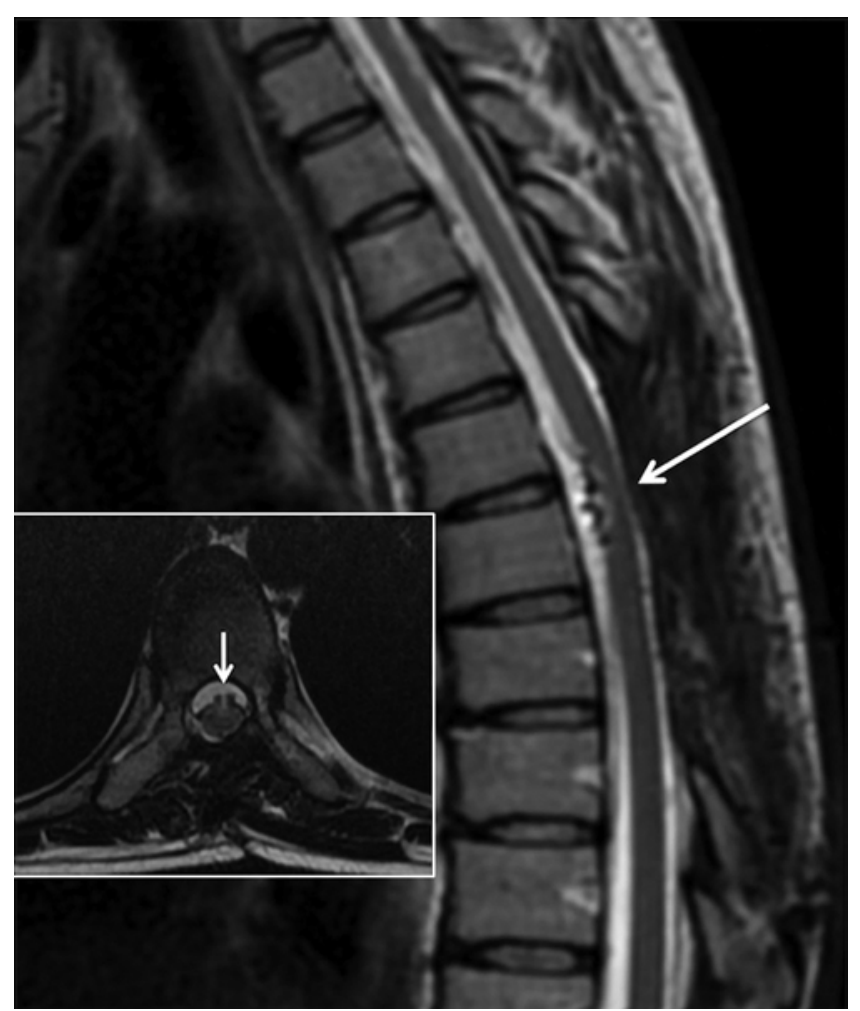

FIG. 3. Postoperative axial (inset) and sagittal T2-weighted MR images obtained 15 months postoperatively, showing adequate reduction of the hernia, minimal metallic artifact provoked by the microstaples, and the stability of the metallic suture (arrows). 
used before in tight spaces for faster and easier dural closure compared with conventional suturing. ${ }^{6,7}$ Although the herniated cord tissue is supposed to be functionless because of chronic ischemia, in this case the patient did not tolerate the presumably insignificant mass effect produced by the introduction of a thin membrane under the cord in contact with the herniated tissue.

To our knowledge, this is a novel technique that has not been previously reported as an option for repairing the dural gap in ISCH. Conveniently, these microstaples produce minimal metallic artifact that does not hinder the quality of follow-up MR images (Fig. 3).

ISCH is an uncommon but relevant cause of progressive thoracic myelopathy and is still misdiagnosed for long periods before surgery is offered. It should be considered among the differential diagnoses in patients with gradual-onset lower-limb weakness of presumed spinal origin. Reaching a diagnosis using MRI is essential to refer patients for surgery before their myelopathy worsens. Our patient experienced a good outcome after reduction of the cord hernia. The use of nonpenetrating titanium microstaples is a technical adjunct that facilitates dural repair and produces minimal MRI artifact, which allows for adequate radiological follow-up.

\section{References}

1. Aydin AL, Sasani M, Erhan B, Sasani H, Ozcan S, Ozer AF: Idiopathic spinal cord herniation at two separate zones of the thoracic spine: the first reported case and literature review. Spine J 11:e9-e14, 2011

2. Berg-Johnsen J, Ilstad E, Kolstad F, Züchner M, Sundseth J: Idiopathic ventral spinal cord herniation: an increasingly recognized cause of thoracic myelopathy. J Cent Nerv Syst Dis 6:85-91, 2014

3. Carter BJ, Griffith BD, Schultz LR, Abdulhak MM, Newman DS, Jain R: Idiopathic spinal cord herniation: an imaging diagnosis with a significant delay. Spine J 15:1943-1948, 2015

4. Groen RJ, Middel B, Meilof JF, de Vos-van de Biezenbos $\mathrm{JB}$, Enting RH, Coppes MH, et al: Operative treatment of anterior thoracic spinal cord herniation: three new cases and an individual patient data meta-analysis of 126 case reports. Neurosurgery 64 (3 Suppl):ons145-ons160, 2009

5. Imagama S, Matsuyama Y, Sakai Y, Nakamura H, Katayama Y, Ito Z, et al: Image classification of idiopathic spinal cord herniation based on symptom severity and surgical outcome: a multicenter study. J Neurosurg Spine 11:310-319, 2009

6. Ito K, Aoyama T, Horiuchi T, Hongo K: Utility of nonpenetrating titanium clips for dural closure during spinal surgery to prevent postoperative cerebrospinal fluid leakage. J Neurosurg Spine 23:812-819, 2015

7. Kaufman BA, Matthews AE, Zwienenberg-Lee M, Lew SM: Spinal dural closure with nonpenetrating titanium clips in pediatric neurosurgery. J Neurosurg Pediatr 6:359-363, 2010

8. Le TC, Grunch BH, Karikari IO, Mehta AI, Owens TR, Gottfried ON, et al: Dorsal thoracic spinal cord herniation: report of an unusual case and review of the literature. Spine J 12:e9-e12, 2012

9. Martinez-del-Campo E, Moon K, Kalb S, Soriano-Baron H, Theodore N: Surgical management of a patient with thoracic spinal cord herniation: case report. Neurosurgery 77:E492E499, 2015

10. Nakamura M, Fujiyoshi K, Tsuji O, Watanabe K, Tsuji T, Ishii K, et al: Long-term surgical outcomes of idiopathic spinal cord herniation. J Orthop Sci 16:347-351, 2011

11. Prada F, Saladino A, Giombini S, Erbetta A, Saini M, DiMeco F, et al: Spinal cord herniation: management and outcome in a series of 12 consecutive patients and review of the literature. Acta Neurochir (Wien) 154:723-730, 2012

12. Samuel N, Goldstein CL, Santaguida C, Fehlings MG: Spontaneous resolution of idiopathic thoracic spinal cord herniation: case report. J Neurosurg Spine 23:306-308, 2015

13. Tekkök IH: Spontaneous spinal cord herniation: case report and review of the literature. Neurosurgery 46:485-492, 2000

14. Vallée B, Mercier P, Menei P, Bouhour F, Fischer C, Fournier $\mathrm{D}$, et al: Ventral transdural herniation of the thoracic spinal cord: surgical treatment in four cases and review of literature. Acta Neurochir (Wien) 141:907-913, 1999

15. Watters MR, Stears JC, Osborn AG, Turner GE, Burton BS, Lillehei K, et al: Transdural spinal cord herniation: imaging and clinical spectra. AJNR Am J Neuroradiol 19:13371344, 1998

16. Wortzman G, Tasker RR, Rewcastle NB, Richardson JC, Pearson FG: Spontaneous incarcerated herniation of the spinal cord into a vertebral body: a unique cause of paraplegia. Case report. J Neurosurg 41:631-635, 1974

\section{Disclosures}

The authors report no conflict of interest concerning the materials or methods used in this study or the findings specified in this paper.

\section{Author Contributions}

Conception and design: Delgado-López, Gil-Polo. Acquisition of data: Delgado-López, Gil-Polo, Martín-Velasco. Analysis and interpretation of data: Delgado-López, Martín-Velasco. Drafting the article: Delgado-López, Gil-Polo, Martín-Velasco. Critically revising the article: Delgado-López, Martín-Velasco, MartínAlonso, Galacho-Harriero, Araus-Galdós. Reviewed submitted version of manuscript: Delgado-López, Gil-Polo, Martín-Alonso, Galacho-Harriero, Araus-Galdós. Administrative/technical/material support: Delgado-López. Video preparation: Delgado-López, Martín-Velasco, Martín-Alonso. Performed intraoperative neurophysiological monitoring: Araus-Galdós.

\section{Supplemental Information Videos}

Video 1. https://vimeo.com/181045496.

\section{Correspondence}

Pedro David Delgado-López, Islas Baleares 3, Burgos 09006, Spain.email: pedrodl@yahoo.com. 